\title{
A recency-based account of the list length effect in free recall
}

\author{
GEOFF WARD \\ University of Essex, Colchester, England
}

\begin{abstract}
Free recall was examined using the overt rehearsalmethodology with lists of 10,20, and 30 words. The standard list length effects were obtained: As list length increased, there was an increase in the number and a decrease in the proportion of words that were recalled. There were significant primacy and recency effects with all list lengths. However, when the data were replotted in terms of when the words were last rehearsed, recall was characterized by extended recency effects, and the data from the different list lengths were superimposed upon one another. These findings support a recency-based account of episodic memory. The list length effect reflects the facts that unrehearsed words are less recent with longer lists, and that with longer lists, a reduced proportion of primacy and middle items may be rehearsed to later positions.
\end{abstract}

In the free recall task, participants are presented with a list of words, one at a time, and are then required to recall the list in any order that they wish. It is customary to illustrate performance on this task by plotting the proportion of words that are recalled by the position of the words on the experimenter's list (the nominal serial position). It is well known that those words that are presented at the beginning and end of the list are recalled more often than those from the middle of the list, and that these recall advantages are known as primacy and recencyeffects, respectively. It is also well established that as the number of words in the list is increased, the proportion of words recalled from the list decreases, even though the actual number of words recalled from the list slightly increases, and this result is known as the list length effect (e.g., Murdock, 1962; Roberts, 1972).

The U-shaped nominal serial position curve has provided the theoretical basis for traditional, dual-store theories of free recall (e.g., Atkinson \& Shiffrin, 1968; Raaijmakers \& Shiffrin, 1981; Shiffrin, 1970) and has led to the characterization of free recall as a two-component task (Glanzer, 1972), with functionally dissociable contributions from short- and long-term memory stores (STS and LTS, respectively). According to these accounts, the recency effect reflects the relatively effortless and accurate retrieval of the last four or so words from a temporary, and highly accessible, STS of limited capacity. The primacy effect and the recall of the middle items reflect retrieval from a qualitatively different LTS, and success is dependent upon the associative strengths of the words in the list to various cues (see Raaijmakers \& Shiffrin, 1981; Shiffrin, 1970). The early list items receive more rehearsals than later list items (Rundus, 1971), resulting in them gaining greater

Correspondence should be addressed to G. Ward, Department of Psychology, University of Essex, Wivenhoe Park, Colchester C04 35Q, England (e-mail: gdward@essex.ac.uk). associative strengths than their less rehearsed neighbors. By contrast, the recall performance for the middle items is sometimes referred to as the asymptote and is typically flat, because the middle items are all assumed to receive, on average, the same number of rehearsals.

The list length effect has also been taken as evidence for the dual-store accounts of free recall. First, the effect of list length is not observed evenly throughout the nominal serial position curve: The proportion of primacy and middle items recalled are greatly reduced by increasing the list length, but recall of the recency items is unaffected (Murdock, 1962). List length can therefore be described as an LTS variable (Glanzer, 1972), as evidenced by its selective contribution to the prerecency, LTS portion of the serial position curve, but not the recency or STS portion of the serial position curve. List length, therefore, serves as a counterexample to STS variables, such as the addition of a filled delay at the end of the list, which reduce the STS portion of the curve while having little or no effect on the LTS portion of the curve (Glanzer \& Cunitz, 1966; Postman \& Phillips, 1965). Second, Murdock (1962) has shown that the recall performance for the middle items or asymptote is inversely proportional to the list length. This finding supports the idea of relative strength models of memory, of which retrieval from LTS is an example (e.g., Gillund \& Shiffrin, 1984; Raaijmakers \& Shiffrin, 1981; Rohrer \& Wixted, 1994; Shiffrin, 1970, 1999; Wixted, Ghadisha, \& Vera, 1997). These accounts assume that the recall of a target is a function of not only the associative strengths of the target item but also the associative strengths of all the list items in the study list. The list length effect is thus a natural consequence of relative strength: As the list length increases, so does the total strength of all the list items, thus reducing the relative strength of any given item and reducing the chance of successfully recalling the list items.

However, a series of studies using the overt rehearsal methodology (e.g., Rundus \& Atkinson, 1970) have pro- 
vided an alternative way of viewing the free recall data. In this procedure, participants are presented with the words for free recall, as before, but are instructed to say out loud any word that is rehearsed or that otherwise comes to mind during the study period. The term rehearsal set (RS) is used to describe the set of words that are rehearsed during the interstimulus intervals following each presentation. Perhaps the most well known finding from using this method is that early list items receive far more rehearsals than later list items, and recall increases as a function of the number of rehearsals for all but the most recent items (e.g., Rundus, 1971; Rundus \& Atkinson, 1970).

What is less well known is that the overt rehearsal methodology shows that recall also decreases as a function of the retention interval. Thus, Rundus (1971) showed that the data that give rise to the U-shaped nominal serial position curve could be transformed into an extended recency function when the data were replotted by when the words were last rehearsed. Similarly, Brodie and Prytulak (1975) have shown that the number of rehearsals and the retention interval of the most recent rehearsal correlated highly (.86) with an item's recall probability. This high multiple correlation of frequency and recency with recall was still observed (.89) when the participants were instructed to selectively rehearse words from different nominal serial positions. In addition, Brodie (1975) and Brodie and Murdock (1977) pioneered the analysis of free recall by the functional serial position. In these analyses, every word in each list is rank ordered in terms of when each word was last rehearsed. The U-shaped nominal serial position curves were transformed into extended recency curves with little or no primacy when the same data were plotted by functional serial position, and this finding held for immediate (Brodie, 1975; Brodie \& Murdock, 1977), delayed (Brodie, 1975), and final (Brodie \& Murdock, 1977) free recall.

Recently, Tan and Ward (2000) have provided a recencybased account of free recall to explain these and related findings. Their account was heavily influenced by the success of the empirical law known as the ratio rule (Baddeley, 1986; Bjork \& Whitten, 1974; Crowder, 1976, 1993; Glenberg, 1984, 1987; Glenberg et al., 1980) at predicting the magnitude of recency effects across a wide range of different experimental situations. The ratio rule predicts that the probability of recalling recency items is proportional to the ratio $(\Delta t / T)$ of the interpresentation interval $(\Delta t)$ to the retention interval $(T)$. Tan and Ward claimed that the ratio rule could be extended to account for both recency and nonrecency items in free recall if episodic memory was viewed as a continuum (with no separate STS and LTS), and the same recency-sensitive retrieval mechanisms operated upon the representations of both the presented items and their rehearsals. In line with this account, they showed that recall performance in free recall was determined by the number, distribution, and recency of items and rehearsals.

The motivation behind the present study was to determine whether a recency-based account of free recall could provide an account of the list length effect in free recall. Potentially, a recency-based account of free recall may offer a simple explanation in terms of selective rehearsal and recency. As the length of a list is increased, the number of items that can be rehearsed constitutes a proportionally decreasing fraction of the list, and those words that are not rehearsed will be increasingly more distant from the end of the list. Since retrieval is assumed to be sensitive to recency, a recency-based account of free recall predicts that there will be a reduction in the proportion of nonrecency words recalled with increasing list length. By contrast, the recency items are rarely rehearsed, and, by definition, are already toward the end of the list. Thus there should be little or no decrease in the recall probabilities for the recency items with increasing list length.

The list length effect was examined in an experiment testing recall performance of lists of 10,20, and 30 words. The overt rehearsal methodology was used, in which the experimenter had access to the subjective order of the list items as well as the experimenter's list order. The data were analyzed by their nominal and functional serial positions (Brodie, 1975) and by the rehearsal set to which the items were last rehearsed (last RS, Rundus, 1971).

\section{METHOD}

\section{Participants}

Twenty-two undergraduate volunteers from the University of Essex participated in this experiment.

\section{Materials and Apparatus}

A total of 478 disyllabic words were used as stimuli. Example words include apple, lady, mission, and platform. The set was obtained by taking the complete set of nouns from the Toronto word pool (Friendly, Franklin, Hoffman, \& Rubin, 1982) and then removing the words error and passage. A subset of 460 words was then assigned to five experimental lists of 10 words, five experimental lists of 20 words, five experimental lists of 30 words, and a practice list of 10 words. A different random order was used for each participant, and no participant received the same word twice during the experiment. The materials were presented using the application Hypercard on an Apple Macintosh computer. A tape recorder was used to record the participants' rehearsals.

\section{Design}

The experiment used a two-factor design. List length was a within-subjects factor with three levels (list length of 10, 20, and 30 words), and serial position within each list was a second within-subjects factor. The proportion of words recalled and the number of rehearsals made to each word were the dependent variables.

\section{Procedure}

The participants were tested individually and were told that they would be presented with a practice list of 10 words, followed by 15 experimental lists of 10,20, and 30 words for free recall. The order of the 15 lists was completely randomized and was different for each participant, so that participants did not know the length of a particular study list in advance. Each list started with a warning tone, followed after $3 \mathrm{sec}$ by a series of words. The words were presented individually in the center of the computer screen for $1 \mathrm{sec}$ and were each followed for $2 \mathrm{sec}$ by a blank screen. The participants were instructed to repeat the words aloud as they appeared and were also instructed to use the interval between the words to rehearse aloud any 
words from the current list that came to mind as they were studying the list. A series of beeps sounded $2 \mathrm{sec}$ after the offset of the last word, which signaled the beginning of the $60-\mathrm{sec}$ recall period.

\section{RESULTS}

Two basic analyses were first performed on the data to confirm the standard list length effects. First, the list length effect was investigated using the proportion of words recalled as the dependent variable. A one-way analysis of variance (ANOVA) with list length as the within-subjects factor with three levels $(10,20$, and 30 words) revealed a highly significant main effect of list length $[F(2,42)=$ $\left.175.0, M S_{\mathrm{e}}=0.002, p<.0001\right]$. The mean proportion of words recalled from the three lists decreased with increasing list length, and were $.52, .36$, and .27 from a $10-$, 20-, and 30- list, respectively. Newman-Keuls comparisons revealed all pairwise differences of means to be significant $(p<.01)$. Second, the list length effect was investigated using the number of words recalled as the dependent variable. A one-way ANOVA with list length as the within-subjects factor $(10,20$, and 30 words) revealed a highly significant main effect of list length $[F(2,42)=$ $\left.54.2, M S_{\mathrm{e}}=0.876, p<.0001\right]$. The mean number of words recalled from the three lists increased with increasing list length, and were 5.22, 7.13, and 8.11 from the 10-, 20-, and 30-word list, respectively. Again, Newman-Keuls comparisons revealed all pairwise differences of means to be significant $(p<.01)$. Thus, the results indicate the standard list length effect: As the length of the list was increased, the proportion of words recalled decreased, although the actual numbers of words recalled increased.

Four detailed analyses were performed on the serial position functions. The first analysis examined the nominal serial position curves, which present the proportion of recalled words by the order in which the items were presented. The second analysis examined the mean number of rehearsals of each word plotted by the input serial position. Third, functional serial position curves ${ }^{1}$ (see, e.g., Brodie, 1975; Tan \& Ward, 2000) were analyzed, which present the proportion of recalled words in terms of the rank order in which the words were last rehearsed. In this analysis, for every participant and every list there was always one item at every functional position, so that there were equal numbers of items that were most recently rehearsed (Functional Serial Position 20) and least recently rehearsed (Functional Serial Position 1). Finally, serial position curves were plotted by last RS, and these present the proportion of recalled words in terms of the RS to which each word was last rehearsed (Rundus, 1971; Tan \& Ward, 2000). Note that the analysis by last RS averages across more data points for later rather than earlier values of last $\mathrm{RS}$, because participants rehearse items that are presented earlier in the list to later rehearsal sets.

\section{Nominal Serial Position}

The mean proportion of words recalled at each nominal serial position for each list length is shown in Figure 1A.
The data for each list length were collapsed into five equal-sized groups and analyzed using three separate $1 \times 5$ within-subjects ANOVAs. These revealed highly significant main effects of serial position $[F s(4,84)=$ $12.55, M S_{\mathrm{e}}=0.040 ; 21.65, M S_{\mathrm{e}}=0.016$; and $21.62, M S_{\mathrm{e}}=$ 0.010 , for Lists Lengths 10,20 , and 30, respectively, all $p \mathrm{~s}<.0001]$. Tukey HSD pairwise comparisons of the means revealed that the first and last means of each list length were significantly different (all $p \mathrm{~s}<.01)$ from each of the three middle means of each list length, demonstrating clear and significant primacy and recency effects within each nominal serial position curve.

In agreement with the traditional list length effect, additional ANOVAs revealed that there were clear and significant effects of list length on the mean proportion of items recalled from the list for the earliest serial positions $\left[F(2,42)=6.30, M S_{\mathrm{e}}=0.017, p<.01\right]$ and for the middle serial positions $\left[F(2,42)=10.21, M S_{\mathrm{e}}=0.012, p<.0001\right]$. However, there was also a small but still significant list length effect for the last sets of words in the list $[F(2,42)=$ $\left.3.94, M S_{\mathrm{e}}=0.008, p<.05\right]$.

\section{Number of Rehearsals}

The mean number of rehearsals of words at each nominal serial position for each list length is shown in Figure 1B. The data for each list length were collapsed into five equal-sized groups and analyzed using three separate $1 \times 5$ within-subjects ANOVAs. These revealed highly significant main effects of serial position $[F s(4,84)=$ $27.29, M S_{\mathrm{e}}=0.991 ; 19.31, M S_{\mathrm{e}}=1.614 ;$ and $20.79, M S_{\mathrm{e}}=$ 1.426 , for Lists Lengths 10,20 , and 30, respectively, all $p$ s $<.0001]$. Tukey HSD pairwise comparisons of the means revealed that the first groups of each list length were significantly different (all $p \mathrm{~s}<.01$ ) from all the other groups. In addition, for the 10 -word lists, the second mean (Serial Position 3-4) was significantly different from the last two groups. These analyses demonstrate that the earlier items in the list receive significantly more rehearsals than the later list items. The mean number of rehearsals per item was approximately constant at $2.14,2.13$, and 2.08 for List Lengths 10,20 , and 30, respectively $[F(2,42)=$ $\left.0.764, M S_{\mathrm{e}}=0.026, p>.05\right]$.

\section{Functional Serial Position}

The mean proportion of words recalled at each functional serial position for each list length is shown in Figure $1 \mathrm{C}$. The data for each list length were collapsed into five equal-sized groups and analyzed using three separate $1 \times 5$ within-subjects ANOVAs. These revealed highly significant main effects of serial position $[F \mathrm{~s}(4,84)=$ $48.17, M S_{\mathrm{e}}=0.028 ; 81.01, M S_{\mathrm{e}}=0.013$; and 74.77, $M S_{\mathrm{e}}=$ 0.011 , for Lists Lengths 10,20 , and 30, respectively, all $p \mathrm{~s}<.0001]$. Tukey HSD pairwise comparisons of the means revealed clear and highly significant extended recency and no primacy with all three list lengths. Recall from later functional serial positions was significantly greater than that from earlier functional serial positions for all list lengths and for all pairwise comparisons except 

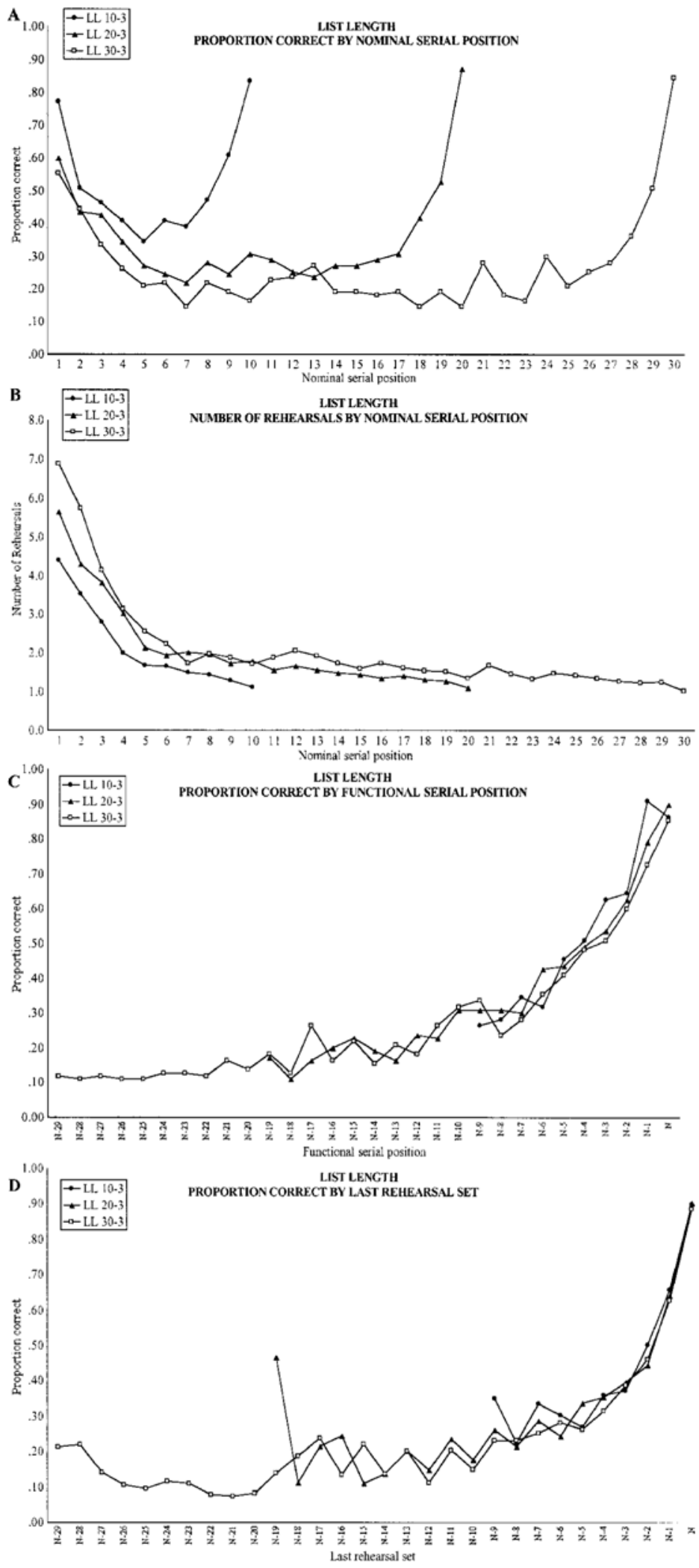

Figure 1. Mean proportion of correct responses for each list length as a function of nominal serial position (A), functional serial position (C), and last rehearsal set to which an item was rehearsed $(D)$; panel $B$ shows the mean number of rehearsals of words plotted by the nominal serial position of the list items. $N$ represents the most recent rehearsal set for each list length. 
for Groups 1 and 2 for List Length 10; Groups 1 and 2 and Groups 2 and 3 for List Length 20; and Groups 1 and 2, Groups 2 and 3, and Groups 1 and 3, for List Length 30. Even in these nonsignificant pairwise comparisons, the recall of more recent words was superior to the recall of earlier words.

Two comparisons were made across list lengths. A 3 (list length) $\times 2$ (functional serial position) within-subjects ANOVA examined performance across the final 10 words in each of the three lists. It showed that there was a nonsignificant main effect of list length $[F(2,42)=2.10$, $\left.M S_{\mathrm{e}}=0.011, p>.05\right]$, a highly significant main effect of serial position $\left[F(1,21)=176.8, M S_{\mathrm{e}}=0.021, p<.0001\right]$, and a nonsignificant interaction $\left[F(2,42)=1.10, M S_{\mathrm{e}}=\right.$ $0.015, p>.05]$. A 2 (list length) $\times 2$ (functional serial position) within-subjects ANOVA examined performance across the penultimate 10 words in each of the two longer lists. It showed that there was a nonsignificantmain effect of list length $\left[F(1,21)=0.15, M S_{\mathrm{e}}=0.010, p>.05\right]$, a near significant main effect of serial position $[F(1,21)=3.82$, $\left.M S_{\mathrm{e}}=0.011, p=.06\right]$, and a nonsignificant interaction $\left[F(1,21)=0.30, M S_{\mathrm{e}}=0.005, p>.05\right]$. These results suggest that the extended recency effects found with each list length are approximately superimposed upon one another when the data are plotted by functional serial position.

\section{Last Rehearsal Set (Last RS)}

The mean proportion of words recalled at each value of last RS for each word frequency is shown in Figure 1D. The data for each list length were initially collapsed into five equal-sized groups. However, as Table 1 shows, the frequency of data points for each list length is greatest at later rehearsal sets: Participants continue to rehearse words presented earlier in the list to later rehearsal sets. This represents a disadvantage with analyzing the data by last RS: The data points for early last RS serial positions are the averages of relatively few occurrences. For example, there are fewer than 50 observations for the first two last RS serial positions in each list length, whereas there are more than 150 observations for the last two last RS serial positions in each list length. In order to avoid rejecting participants from the analyses whose results contained missing cells, the data for the first two groups of serial positions within List Lengths 10 and 20 were combined. A $1 \times 4$ ANOVA with last RS as within-subjects factor revealed significant main effects of last $\mathrm{RS}$ for List Length 10 $\left[F(3,63)=37.00, M S_{\mathrm{e}}=0.030, p<.0001\right]$ and List Length $20\left[F(3,63)=88.97, M S_{\mathrm{e}}=0.009, p<.0001\right]$. A $1 \times 5$ ANOVA with last RS as within-subjects factor revealed significant main effects of last $\mathrm{RS}\left[F_{\mathrm{S}}(4,84)=\right.$ $\left.59.24, M S_{\mathrm{e}}=0.009, p<.0001\right]$ for List Length 30. Tukey HSD pairwise comparisons of the means revealed clear and highly significant extended recency and no primacy with all three list lengths. Recall from later last RS serial positions was significantly greater than recall from earlier last RS serial positions for all list lengths and for all pairwise comparisons except for Groups 1 and 2 and Groups 2 and 3 for List Length 10; Groups 1 and 2 for

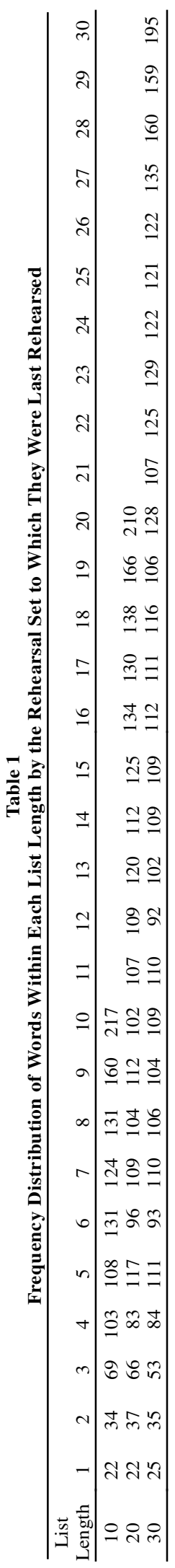


List Length 20; and Groups 1 and 2, 1 and 3, 2 and 3, and 3 and 4 for List Length 30.

Two comparisons were made across list lengths. A 3 (list length) $\times 2$ (last RS serial position) within-subjects ANOVA examined performance across the final 10 words in each of the three lists. It showed a nonsignificant main effect of list length $\left[F(2,42)=0.47, M S_{\mathrm{e}}=0.007, p>\right.$ .05], a highly significant main effect of serial position $\left[F(1,21)=237.1, M S_{\mathrm{e}}=0.011, p<.0001\right]$, and a nonsignificant interaction $\left[F(2,42)=0.01, M S_{\mathrm{e}}=0.013\right.$, $p>.05$ ]. A 2 (list length) $\times 2$ (last RS serial position) within-subjects ANOVA examined performance across the penultimate 10 words in each of the two longer lists. It showed a nonsignificant main effect of list length $\left[F(1,21)=0.00, M S_{\mathrm{e}}=0.009, p>.05\right]$, a nonsignificant main effect of serial position $\left[F(1,21)=0.04, M S_{\mathrm{e}}=\right.$ $0.014, p=.06]$, and a nonsignificantinteraction $[F(1,21)=$ $\left.1.16, M S_{\mathrm{e}}=0.006, p>.05\right]$. These results suggest that the recency effects found with each list length were again approximately superimposed upon one another when the data are plotted by last RS serial position. Furthermore, the items in RSs 11-15 from the end were not significantly better recalled than those in the 16-20 RSs from the end.

\section{DISCUSSION}

A clear and substantial list length effect was observed in free recall. The proportion of words recalled decreased with increasing list lengths, and this effect was the result of ever-smaller increases in the actual number of words recalled with longer lists (Murdock, 1962; Roberts, 1972).

When the data are examined by the nominal serial position (Figure 1A), the results can be readily explained in terms of the dual-store theories: Recency could reflect the direct output of STS, whereas the rest of each serial position curve could reflect a search through LTS. The primacy effects may be assumed to reflect the increase in associative strength afforded to the early list items due to the greater numbers of rehearsals that these words receive (Figure 1D). Furthermore, the asymptote is approximately flat (at least for longer lists) and is at a value that is inversely related to the list length. These findings could be taken as evidence that the search through LTS is insensitive to recency, but is sensitive to the associative strength of the items within the list relative to the total associative strength of all the list items.

However, the nominal serial position curves take into account only the experimenter's view of the list. A more accurate reflection of the participants' memory of the list should also take into account the number and the ordering of the participants' rehearsals. When the participants' rehearsals are included in the analyses, a completely different picture of the underlying processes in single-trial free recall is revealed. The functional serial position curves are monotonic, with extended recency and little or no primacy, and when recency-justified for different list lengths, the curves are approximately superimposed upon one another. The one exception appears to be the one-item pri- macy effects that are apparent in the very first item in each list length on a small number of occurrences. This effect may be genuine and reflect the distinctiveness (e.g., Neath, 1993) afforded to the very first items in the list or may reflect the occasional unwillingness or inability by participants to say out loud all their rehearsals.

These latter findings appear to be at odds with the predictions of dual-store accounts of free recall. First, recall appears to be sensitive to recency throughout the entire list (and not just the STS portion of the curve). This contrasts with the assumptions of dual-store accounts that recall from the LTS portion of the curve is insensitive to recency. Second, there is little or no effect of proactive interference from earlier items within the list upon later list items. Recall performance from the last $10 \mathrm{RSs}$ and functional serial positions appears to be nearly identical regardless of whether there are 0,10 , or 20 previous words or RSs. Such a finding is at odds with relative strength models of memory, in which recall is a function of the associative strength of a given item relative to the total strength of the list.

Instead, the list length effect can be reformulated in terms of recency and selective rehearsal. As the list length is increased, unrehearsed words will end up further from the end of the list, and less recent words will be less well recalled. In addition, since the number of words that can be rehearsed in a given RS can be assumed to be approximately constant, a smaller proportion of primacy and asymptote items can be rehearsed toward the end of the list. Figures 1C and 1D show that the same number of words can be recalled from the last 10 or so RSs or functional serial positions. Additional words may be recalled from earlier RSs or functional serial positions, where they exist, so that increasing the list length increases the total number of words recalled. However, recall of these additional, earlier words is at a reduced probability: The overall proportion of words recalled from longer lists decreases with increased list length.

This recency-based explanation of list length in free recall is supported by the widespread finding of extended recency effects over time periods ranging from tenths of seconds (Neath \& Crowder, 1996) to weeks or even months (Baddeley \& Hitch, 1977; Rubin, 1982). They also occur when the interitem interval is filled with a demanding task that is expected to overwrite STS (e.g., Baddeley \& Hitch, 1974, 1977; Glenberg et al., 1980; Watkins, Neath, \& Sechler, 1989). These findings suggest that recency effects are a general property of episodic memory (Ward, 2001) and that recency effects occur over all time frames.

In addition, the interpretation of the list length effect (a classic LTS variable, Glanzer, 1972) in terms of a recency-based single-store account provides additional support for the recent reexamination of other LTS variables in free recall. With the overt rehearsal methodology, the effects of presentation rate (Brodie, 1975; Tan \& Ward, 2000) and word frequency in pure and mixed lists (Tan \& Ward, 2000; Ward, Woodward, Stevens, \&, Stinson, 2002) were found to effect the selective rehearsal of early list items to later serial positions. 
It should be noted, however, that the single-store, recencybased perspective on these findings is just one way of interpreting these data. Laming (1999) has recently tested the idea of distinct storage mechanisms in memory. He reexamined the single-trial free recall and latency data of Murdock and Okada (1970) that has traditionally been used to promote dual-store accounts of memory. He argued that dual-store accounts of memory emphasize the higher accessibility of those words output from STS compared with those items retrieved from LTS. Consistent with these STS accounts, he found that the last words in the list were indeed often output quickly and early in recall. However, a detailed analysis of the order and timing of participants' recalls suggested that recall tended to start by using either the end of the list or the initial warning tone as a cue, and once the first word was recalled, it effectively cued successive list items (for related analyses, see also Howard \& Kahana, 1999; Kahana, 1996). On the basis of these two findings, Laming proposed a detailed single-store explanation that approximately fitted the recall and latency data and concluded that a "separate shortterm store is no better than make believe" (p. 425). The danger, therefore, is that without a formal model to evaluate the predictions of the recency-based explanation, the data may be equally well explained by both dual-store and single-store theories.

However, it is possible that overt rehearsals may offer a route to deeper understanding of free recall. One use for the patterns of rehearsals is that they may be considered to be data points that need to be explained by a complete account of free recall, and as such may provide a test-bed for future and existing theories. Alternatively, the words rehearsed at each RS may be considered to be mini-free recalls. An understanding of the mechanisms that determine the patterns of rehearsals may then be used to provide an understanding of the mechanisms that determine the patterns of recalls. An analysis of the patterns of rehearsals provides us with an insight into the development of the Ushaped serial position curve. Tan and Ward (2000) analyzed the serial position curves for the proportion of words that are rehearsed at least once at RSs 4, 7, 14, and 20. At RS 4, each of the first three words was rehearsed equally often. At RS 7, the distribution of rehearsals resembles the serial position curve in immediate serial recall, with extended primacy and one- or two-item recency. This finding provides evidence that some common memory mechanisms may underpin both immediate serial recall and free recall (for contrasting views on this issue, see Baddeley, 1986, and Ward, 2001). Later, at RSs 14 and 24, there is a Ushaped distribution of rehearsals, with extended primacy and recency effects. From RS 7 onward, it appears that the probability of rehearsing a word in successive RSs is greater for early list items than for later list items, and this may be because the early list items are rehearsed on more prior occasions. Thus, in line with viewing rehearsals as mini-free recalls, it appears that the proportion of words rehearsed at any given RS is itself related to both the recency and the number of prior rehearsals.
An analysis of the output order provides further evidence that patterns of data observed at recall may be traced to the patterns of data observed in the rehearsals. Kahana and his colleagues (Howard \& Kahana, 1999, 2002; Kahana, 1996) have shown that the probability of recalling a word increases if the immediately preceding word recalled was a semantically related word or if it was from the immediately preceding position in the study list. These findings were argued to be the result of interitem associations that were encoded during the list presentations. However, it has been known since Rundus (1971) that the probability that a presented word will be rehearsed on the following RS is influenced by the distinctiveness and the meaning of both the presented word and those words that are currently being rehearsed. Rundus showed that distinctive words (words presented in red ink set in a list presented mainly in black ink) and words from neighboring serial positions were more likely to be rehearsed and then subsequently recalled than were the other words in the list. In a separate experiment, Rundus also showed that a word was more likely to be rehearsed and then recalled if it was first presented at a time when words from the same semantic category were currently being rehearsed. The relationship between the output order at recall and rehearsals was also examined recently by Ward et al. (2002). They examined the output order for free recall of lists of 20 high- and low-frequency words. In one experiment, successive recalls occurred on 375 occasions, throughout the nominal serial position curve. However, the successive recalls tended to be rehearsed toward the very end of the list (220 occurrences were rehearsed to the last three RSs), and these words that were recalled in the same order as in the study list also tended to be corehearsed (214 were corehearsed to the same most recent RS). Similar results were found in the second experiment. These analyses provide further evidence that the patterns of words rehearsed determine the patterns of words recalled.

Finally, it should be stated that the overt rehearsal method has its limitations. One difficulty is that not all participants are willing or able to say out loud all their rehearsals, and this may result in the underestimation of the effect of rehearsals on free recall. Second, it should be acknowledged that the experimenter has little or no control over which words the participants decide to rehearse. Theoretically, it is possible that the relationship between recall and rehearsals could have been due to participants selectively rehearsing words that were inherently more memorable, resulting in rehearsed words consequently being recalled more often. However, the control rehearsal procedure of Murdock and Metcalfe (1978) suggests that the relationship between rehearsals and recalls is unlikely to be due to such item selection artifacts. Murdock and Metcalfe showed that there was essentially no difference in the relationship between rehearsals and recalls when a computer program was used to repeat the words (controlled rehearsals) and when participants selected the words to rehearse themselves. The standard nominal and functional serial position curves were obtained from both proce- 
dures, even though in the control rehearsal procedure the participants could not select which words would be repeated. However, one problem with the participants selecting the words to rehearse is that the resulting data are necessarily distributed unevenly, and this renders statistical analysis of some interesting comparisons difficult.

In summary, the list length effect in free recall is interpreted as a result of selective rehearsal within a recencybased account of free recall. In support of this finding, the probability of recalling a word was shown to be an inverse function of when it was last rehearsed, and when recencyjustified was essentially independent of the overall list length. As the list length increases, a smaller proportion of words can be rehearsed, and those words that are not rehearsed end up further from the end of the list. This singlestore interpretation of the data is preferred, but formal comparisons with other accounts may have to wait until an explicit recency-based model is developed.

\section{REFERENCES}

ATKInson, R. C., \& SHIFfrin, R. M. (1968). Human memory: A proposed system and its control processes. In K. W. Spence \& J. T. Spence (Eds.), The psychologyoflearning and motivation(Vol. 2, pp. 89-195). New York: Academic Press.

BADDELEy, A. D. (1986). Working memory. Oxford: Clarendon.

BADDEley, A. D., \& Hitch, G. J. (1974). Working memory. In G. H. Bower (Ed.), Recent advances in learning and motivation (Vol. 8, pp. 47-90). London: Academic Press.

BADDELEY, A. D., \& Hitch, G. J. (1977). Recency re-examined. In S. Dornic (Ed.), Attention and performance VI (pp. 647-667). Hillsdale, NJ: Erlbaum.

BJork, R. A., \& Whitten, W. B. (1974). Recency-sensitive retrieval processes in long-term free recall. Cognitive Psychology, 6, 173-189.

BRodie, D. A. (1975). Free recall measures of short-term store: Are rehearsal and order of recall data necessary? Memory \& Cognition, $\mathbf{3}$, 653-662.

Brodie, D. A., \& Murdock, B. B. (1977). Effect of presentation time on nominal and functional serial-position curves of free recall. Journal of Verbal Learning \& Verbal Behavior, 16, 185-200.

Brodie, D. A., \& PrytulaK, L. S. (1975). Free recall curves: Nothing but rehearsing some items more or recalling them sooner? Journal of Verbal Learning \& Verbal Behavior, 14, 549-563.

Crowder, R. G. (1976). Principles of learning and memory. Hillsdale, NJ: Erlbaum.

Crowder, R. G. (1993). Short-term memory: Where do we stand? Memory \& Cognition, 21, 142-145.

Friendly, M., Franklin, P. E., Hoffman, D., \& Rubin, D. C. (1982). Norms for the Toronto Word Pool: Norms for imagery, concreteness, orthographic variables, and grammatical usage for 1,080 words. $B e$ havior Research Methods \& Instrumentation, 14, 375-399.

Gillund, G., \& Shiffrin, R. M. (1984). A retrieval model for both recognition and recall. Psychological Review, 91, 1-67.

GLANZER,M. (1972). Storage mechanisms in recall. In G. H. Bower (Ed.), The psychology of learning and motivation: Advances in research and theory (Vol. 5, pp. 129-193). New York: Academic Press.

Glanzer, M., \& CUNITZ, A. R. (1966). Two storage mechanisms in free recall. Journal of Verbal Learning \& Verbal Behavior, 5, 351-360.

GLENBERG, A. M. (1984). A retrieval account of the long-term modality effect. Journal of Experimental Psychology: Learning, Memory, \& Cognition, 10, 16-31.

GLENBERG, A. M. (1987). Temporal context and recency. In D. S. Gorfein \& Robert R. Hoffman (Eds.), Memory and Learning: The Ebbinghaus Centennial Conference (pp. 173-190). Hillsdale, NJ: Erlbaum.

Glenberg, A. M., Bradley, M. M., Stevenson, J. A., Kraus, T. A. TkachuK, M. J., Gretz, A. L., Fish, J. H., \& Turpin, B. M. (1980).
A two-process account of long-term serial position effects. Journal of Experimental Psychology: Human Learning \& Memory, 6, 355-369. HowARD, M. W., \& KAHANA, M. J. (1999). Contextual variability and serial position effects in free recall. Journal of Experimental Psychology: Learning, Memory, \& Cognition, 25, 923-941.

HoWARD, M. W., \& KAHANA, M. J. (2002). When does semantic similarity help episodic retrieval? Journal of Memory \& Language, 46, 85-98.

KaHANA, M. J. (1996). Associative retrieval processes in free recall. Memory \& Cognition, 24, 103-109.

LAMING, D. (1999). Testing the idea of distinct storage mechanisms in memory. International Journal of Psychology, 34, 419-426.

MuRdock, B. B. (1962). The serial position curve of free recall. Journal of Experimental Psychology, 64, 482-488.

Murdock, B. B., \& Metcalfe, J. (1978). Controlled rehearsal in singletrial free recall. Journal of Verbal Learning \& Verbal Behavior, 8, 665676.

Murdock, B. B., \& OKadA, R. (1970). Interresponse times in singletrial free recall. Journal of Experimental Psychology, 86, 263-267.

NEATH, I. (1993). Distinctiveness and serial position effects in recognition. Memory \& Cognition, 21, 689-698.

Neath, I., \& Crowder, R. G. (1996). Distinctiveness and very shortterm serial position effects. Memory, 4, 225-242.

Postman, L., \& Phillips, L. W. (1965). Short-term temporal changes in free recall. Quarterly Journal of Experimental Psychology, 17, 132-138.

RAaijmakers, J. G. W., \& Shiffrin, R. M. (1981). Search of associative memory. Psychological Review, 88, 93-134.

RoberTs, W. A. (1972). Free recall of word lists varying in length and rate of presentation: A test of total-time hypotheses. Journal of Experimental Psychology, 92, 365-372.

Rohrer, D., \& WiXTED, J. T. (1994). An analysis of latency and interresponse time in free recall. Memory \& Cognition, 22, 511-524.

RuBin, D. C. (1982). On the retention function for autobiographical memory. Journal of Verbal Learning \& Verbal Behaviour, 21, 21-38.

Rundus, D. (1971). Analysis of rehearsal processes in free recall. Journal of Experimental Psychology, 89, 63-77.

Rundus, D., \& ATKInson, R. C. (1970). Rehearsal processes in free recall: A procedure for direct observation. Journal of Verbal Learning \& Verbal Behavior, 9, 99-105.

Shiffrin, R. M. (1970). Memory search. In D. A. Norman (Ed.), Models of memory (pp. 375-447). New York: Academic Press.

ShIfFrin, R. M. (1999). Thirty years of memory. In C. Izawa (Ed.), On human memory: Evolution, progress and reflections on the 30th Anniversary of the Atkinson-Shiffrinmodel (pp. 17-34). London: Erlbaum.

TAN, L., \& WARD, G. (2000). A recency-based account of primacy effects in free recall. Journal of Experimental Psychology: Learning, Memory, \& Cognition, 26, 1589-1625.

WARD, G. (2001). A critique of the working memory model. In J. Andrade (Ed.), Working memory in perspective (pp. 219-239). Hove: Psychology Press.

Ward, G., Woodward, G., Stevens, A., \& Stinson, C. (2002). Using overt rehersals to explain word frequency effects in free recall. Manuscript submitted for publication.

Watkins, M. J., Neath, I., \& Sechler, E. S. (1989). Recency effect in recall of a word list when an immediate memory task is performed after each word presentation. American Journal of Psychology, 102, 265-270.

WiXted, J. T., GHadisha, H., \& Vera, R. (1997). Recall latency following pure- and mixed-strength lists: A direct test of the relative strength model of free recall. Journal of Experimental Psychology: Learning, Memory, \& Cognition, 23, 523-538.

\section{NOTE}

1. The functional serial positions reported in this paper are only very close approximations to the participants' actual functional serial order, in that the functional order of items that shared identical last rehearsal sets was determined by randomly allocating these words to neighboring functional serial positions.

(Manuscript received June 11, 2001; revision accepted for publication April 5, 2002.) 